Published in final edited form as:

Transl Res. 2017 June ; 184: 101-107. doi:10.1016/j.trs1.2017.02.004.

\title{
Smoking and the Risk of Type 2 Diabetes
}

Judith Maddatu ${ }^{1}$, Emily Anderson-Baucum ${ }^{5}$, and Carmella Evans-Molina ${ }^{1,2,3,4,6}$

${ }^{1}$ Department of Medicine, Indiana University School of Medicine, Indianapolis, IN 46202

2Department of Cellular and Integrative Physiology, Indiana University School of Medicine, Indianapolis, IN 46202

${ }^{3}$ Department of Biochemistry and Molecular Biology, Indiana University School of Medicine, Indianapolis, IN 46202

${ }^{4}$ Herman B Wells Center for Pediatric Research, Indiana University School of Medicine, Indianapolis, IN 46202

5,6Indiana Biosciences Research Institute, Indianapolis, IN 46202

${ }^{6}$ Roudebush VA Medical Center, Indianapolis, IN 46202

\begin{abstract}
Despite accumulating evidence demonstrating strong epidemiological and mechanistic associations between cigarette smoking, hyperglycemia, and the development of type 2 diabetes, tobacco abuse has not been uniformly recognized as a modifiable risk factor in diabetes prevention or screening strategies. In this review, we highlight population-based studies that have linked cigarette smoking with an increased risk of type 2 diabetes and summarize clinical and preclinical studies offering insight into mechanisms through which cigarette smoking and nicotine exposure impact body composition, insulin sensitivity, and pancreatic $\beta$ cell function. Key questions for future studies are identified and strategies for smoking cessation as a means to decrease diabetes risk are discussed.
\end{abstract}

\section{Keywords}

diabetes mellitus; cigarette smoking; nicotine; tobacco

\section{Introduction}

Worldwide, diabetes mellitus affects nearly 422 million individuals and is directly responsible for 1.5 million deaths while indirectly contributing to an additional 17.5 million deaths each year [1]. Type 2 diabetes (T2D) accounts for 90-95\% of diabetes cases and is

To whom correspondence should be addressed: Carmella Evans-Molina, MD, PhD, Indiana University School of Medicine, 635 Barnhill Drive MS 2031A, Indianapolis, IN, USA;, Tel: (317) 274-4145, Fax: (317) 274-4107, cevansmo@iu.edu.

Publisher's Disclaimer: This is a PDF file of an unedited manuscript that has been accepted for publication. As a service to our customers we are providing this early version of the manuscript. The manuscript will undergo copyediting, typesetting, and review of the resulting proof before it is published in its final citable form. Please note that during the production process errors may be discovered which could affect the content, and all legal disclaimers that apply to the journal pertain. 
caused by insulin resistance and progressive loss of $\beta$ cell function and mass. Because T2D risk is strongly linked to environmental, nutritional, and lifestyle determinants, targeting known risk factors through early lifestyle modification remains the most effective strategy for decreasing disease prevalence and mortality [1]. According to the 2014 Surgeon General's Report, smoking increases the risk of T2D by $30-40 \%$ for active smokers compared to non-smokers, suggesting that smoking cessation should be emphasized as an essential public health strategy to combat the global epidemic of diabetes [2]. The World Health Organization recognizes smoking as a preventable risk factor for T2D and endorses smoking avoidance/cessasion as part of their lifestyle recommendations [3]. However, both the American Diabetes Association and the International Diabetes Foundation do not currently include smoking as a modifiable risk factor for diabetes development or consider smoking status as factor that should prompt diabetes screening [4, 5]. In this review, we highlight key population-based studies that have linked cigarette smoking with an increased risk of T2D and summarize clinical and preclinical studies that provide insight into the mechanisms through which cigarette smoking impacts metabolic health and glucose homeostasis.

\section{Epidemiological evidence linking cigarette smoking and diabetes}

A variety of epidemiological studies have demonstrated associations between cigarette smoking and the development of T2D [6-8]. The Health Professionals' Follow-Up Study analyzed data from over 40,000 American male health care professionals who were followed with biannual surveys for over six years from 1986-1992. In this study, men who smoked 25 or more cigarettes per day had a relative risk of incident diabetes of 1.94 (95\% confidence interval (CI) 1.25, 3.03) compared to non-smokers [8]. Similar results have been shown in other ethnic groups, including a study of nearly 50,000 Chinese men who were followed on average for 5.4 years. In this cohort, those who smoked more than 20 cigarettes per day had an elevated hazard ratio of incident T2D of 1.25 (95\% CI: 1.00, 1.56), while men with a $\geq 40$ pack-year history of smoking had an elevated hazard of T2D of 1.28 (95\%CI: 1.04, 1.57) [9]. In a study of U.S. postmenopausal females, those who smoked on average 16.2 cigarettes per day exhibited a 1.28-fold increased risk of new diabetes (95\% CI: 1.20, 1.36). Risk was mitigated in those who stopped smoking; after 10 years of cessation, the risk of diabetes became equivalent to that of never-smokers [10]. A similar analysis was performed in a Korean cohort of 1,236,443 men and women who were aged 30-95 years at baseline and followed prospectively over 14 years. Smoking was associated with an increased risk for diabetes treatment, hospitalization, and mortality among both men and women, and risk increased in a dose-dependent manner with the number of cigarettes smoked per day. Interestingly, data from this cohort also suggested an increased risk for men compared to women [11].

Studies have also examined associations between smoking and glycemia. In a large crosssectional study of 2704 men and 3385 women followed in the European Investigation into Cancer (EPIC-Norfolk) study, cigarette smoking was independently associated with higher hemoglobin A1c (HbA1c) concentrations, with both male and female smokers exhibiting similar changes in $\mathrm{HbA} 1 \mathrm{c}$ values. This analysis demonstrated that $\mathrm{HbA} 1 \mathrm{C}$ rose by $0.12 \%$ per 20 pack-years of smoking in participants of both genders [12]. Similarly, data from the 
National Health and Nutrition Examination survey, which included 17,287 adults without diabetes, showed that the mean age-adjusted $\mathrm{HbA1C}$ was higher in patients with elevated circulating levels of the nicotine metabolite, cotinine, while smokers exhibited a 7\% increase in HbA1c compared to those who had never smoked [13].

\section{Smoking Leads to a Variety of Chemical Exposures}

Cigarettes and other smoking products contain a mix of chemical additives with the potential to impact metabolic health. Nicotine is one of the major bioactive substances in cigarettes and is among the most widely consumed additive. Nicotine is an alkaloid naturally produced by the tobacco plant that binds nicotinic acetylcholine receptors, found throughout neuronal and non-neuronal or visceral organs. These receptors participate in signaling within the central and peripheral nervous system and in a number of metabolic tissues, including pancreatic islets, adipose tissue, macrophages, liver, and skeletal muscle [14-17]. Nicotine has been shown to directly alter glucose homeostasis [18], suggesting an important role for this additive in the development of T2D. Cigarette smoking also results in increased blood serum levels of heavy metals such as lead, arsenic, and cadmium [19]. However, studies of the impact of these substances on glucose homeostasis have yielded somewhat inconsistent results. For instance, exposure to low environmental levels of inorganic arsenic in 3602 Korean adults increased the prevalence of diabetes. Additionally, glucose tolerance was inversely correlated with urinary arsenic levels, suggesting a role for the heavy metal in the development of diabetes [20]. In a Bangladeshi study, the odds ratio of diabetes was 8.83 in male smokers with arsenic blood serum levels of $\geq 15.5 \mu \mathrm{g} / \mathrm{L}$ compared to male smokers with lower arsenic levels [21]. Likewise, participants from the Canadian Health Measures survey with high urinary arsenic levels ( $\geq 22.99 \mu \mathrm{g} / \mathrm{L}$ ) showed a nearly 2 -fold increased risk of T2D compared to those with urinary arsenic levels of less than $5.71 \mu \mathrm{g} / \mathrm{L}$ [22]. In contrast, no significant relationship was found between levels of lead, mercury, or cadmium, and diabetes or measures of $\beta$ cell function in another study of Korean men and women, even when considering the sum exposure of heavy metals [23]. Likewise, only limited data could support an association between arsenic and diabetes in chronically exposed populations in Taiwan and Bangladesh [24].

\section{Cigarette smoking impacts body weight and composition, peripheral insulin sensitivity, and pancreatic $\beta$ cell function}

Whereas epidemiological studies have tested associations between smoking and diabetes development, a number of studies have also investigated mechanistic underpinnings of these associations. In aggregate, data from these studies suggest that smoking is associated with deleterious changes in body composition, despite being linked to reduced body weight [25]. Individuals who smoked $>20$ cigarettes per day had an adjusted odds ratio for abdominal obesity of 1.93 (95\% CI: 1.16 to 3.21) as compared to never-smokers [26]. Cross-sectional data from 21,828 men and women aged 45 to 79 years in the United Kingdom demonstrated that smokers had higher waist-to-hip ratios as compared to non-smokers, and this measure was directly correlated with the amount of smoking [27]. Furthermore, in a cross-sectional study of 513 Japanese men, greater lifetime smoking exhibited a significant and positive 
association with higher waist-to-hip ratio and the visceral adipose to subcutaneous adipose ratio, assessed by computerized tomography (CT) scans [25]. These findings support the general notion that smoking is linked to adverse fat distribution. Interestingly, changes in body composition associated with cigarette smoking appear to be driven primarily by nicotine signaling, both centrally and peripherally [reviewed in [16]]

Consistent with these changes in body composition, smoking acutely worsened glucose tolerance and the insulin sensitivity index in twenty chronic smokers who had paired oral glucose tolerance tests performed after smoking and under control conditions [28]. In persons with established diabetes, euglycemic hyperinsulinemic clamp analyses revealed that total body glucose disposal was reduced in smokers compared to those who did not smoke [29]. In addition, data support a direct effect of nicotine on glucose homeostasis. In this regard, results from hyperglycemic-hyperinsulinemic clamp analyses performed on subjects with established T2D revealed that active smoking as well as acute transdermal nicotine patch administration led to decreased insulin action [18].

In addition to the above effects on body composition and peripheral insulin signaling, Clinical studies also suggest that smoking impairs measures of $\beta$ cell function. Among 1,199 Japanese men aged 30-79, the incidence of impaired insulin secretion, as represented by a change in the insulinogenic index during a 75-gram oral glucose tolerance test over a mean follow-up of 2.8 years, was 1.06 in ex-smokers versus 1.95 in current smokers, as compared to never-smokers. Furthermore, the number of pack-years of smoking was found to dosedependently impair $\beta$ cell function [30]. Separately, Ostgren and colleagues studied nearly 260 Swedish men and found that current cigarette smokers had lower $\beta$ cell function, as measured by the homeostatic model assessment method (HOMA- $\beta$ ), compared to never smokers (58.1 vs. 90.1; 95\% CI: $17.8-43.5, \mathrm{p}<0.001)$. This difference remained significant even after adjustment for age, body mass index, alcohol intake, and physical activity. Interestingly, results from this study suggested dichotomous effects by gender, as no significant relationships were found between smoking and $\beta$ cell function among nearly 350 female never and current smokers [31].

\section{Molecular mechanisms underlying the development of altered glucose homeostasis in smokers}

To gain insight into the effects of smoking on peripheral insulin signaling, Bergman and colleagues analyzed skeletal muscle biopsy specimens from smokers and nonsmokers and found that smokers had increased Ser636 phosphorylation of IRS-1, a known inhibitory modification with negative effects on insulin sensitivity. Smokers also exhibited decreased expression of peroxisome proliferator-activated receptor-gamma (PPAR- $\gamma$ ), a transcription factor known to promote insulin sensitivity [32]. A later study from this same group characterized the in vitro effects of nicotine on skeletal muscle cultures and showed that nicotine exposure resulted in increased IRS-1 Ser636 phosphorylation and activation of mTOR and MAPK signaling, while rapamycin-induced inhibition of mTOR was able to reverse nicotine-induced alterations in IRS-1 signaling [33]. 
Nicotine has also been reported to increase lipolysis from adipose tissue [34] by activating AMP-activated protein kinase a 2 (AMPKa2) in adipocytes, leading to increased phosphorylation and proteosomal degradation of MAP kinase phosphatase-1 (MKP1). Nicotine-induced reductions in MKP1 resulted in activation of p38 mitogen-activated protein kinase and c-Jun $\mathrm{N}$-terminal kinase, ultimately promoting IRS-1 degradation and loss of insulin-mediated inhibition of lipolysis [35]. Consistent with these observations, serum triglyceride levels have been shown to be higher in smokers compared to nonsmokers [36]. Furthermore, cigarette smoking was independently associated with the onset of nonalcoholic fatty liver disease (NAFLD) [37]

Smoking may also impact insulin sensitivity through additional epigenetic mechanisms. Analysis of 432 blood samples from subjects in the Northern Sweden Population Health Study revealed that 95 DNA methylation sites within 66 distinct chromosomal regions were differentially methylated in smokers. Interestingly, genes associated with "insulin receptor binding" and "negative regulation of glucose import" were enriched within the dataset, suggesting that smoking-induced diabetes susceptibility may arise from aberrant methylation of DNA [38]. In support of this theory, a recent paper found that cigarette smoking is associated with altered methylation patterns in several previously identified diabetes-related genes [39]

In contrast to studies testing molecular associations between smoking and reduced insulin sensitivity, considerably less is known about how smoking impacts pancreatic $\beta$ cell function. Nicotinic receptors have been reported on pre-synaptic sympathetic nerve terminals and postsynaptic receptors within islets, while nicotinic receptor agonism and antagonism have been shown to modulate insulin secretion. Stagner and Samols performed a series of experiments using an in vitro canine whole pancreas perifusion model. Acutely, perifusion of canine pancreas with nicotine resulted in transient stimulation of insulin secretion, which was blocked by ganglionic postsynaptic nicotinic receptor blockade using alpha-bungarotoxin. Interestingly, pre-synaptic receptor blockade also led to decreased insulin secretion [40]. However, in another study, contrasting effects were observed in isolated rat islets, where insulin secretion was increased by alpha-bungarotoxin. Moreover, nicotine suppressed alpha-bungarotoxin-induced increase in insulin secretion [41]. In yet another analysis, acute nicotine treatment also moderately decreased insulin secretion in human islets, while chronic treatment for $48 \mathrm{hrs}$ led to a significant reduction in insulin secretion [42]. Some of these discrepancies may be related to species-related differences as well as differences between experiments performed using a pancreas perifusion system and isolated islets. However, available data fail to provide clarity regarding the effects of nicotine on normal pancreatic $\beta$ cell function. As such, additional mechanistic studies are warranted to more completely understand the physiology of nicotinic signaling in the islet as well as the clinical association between smoking and reduced $\beta$ cell function $[30,31]$.

Not withstanding these uncertainties, smoking and nicotine exposure may induce a proinflammatory metabolic state that would be expected to impact both insulin sensitivity and $\beta$ cell function. Nicotine has been shown to decrease activity of free radical scavenging enzymes, in turn increasing generation of hydroxyl free radicals by increased superoxide anion and hydrogen peroxide [43]. Furthermore, skeletal muscle expression of monocyte 
chemotactic protein-1 was increased in smokers compared to non-smokers [32]. In healthy middle-aged non-obese men, long-term nicotine gum chewers (NGCs) had greater plasminogen activator inhibitor-1 activity compared to non-smoking controls [36]. Smoking also causes an endogenous stress response characterized by increased circulating levels of cortisol, catecholamines, and growth hormone that can impact glucose homeostasis at both the level of the $\beta$ cell function and peripheral tissues $[44,45]$.

\section{Alternative smoking products and T2D risk}

Of note, the increased risk for T2D development associated with tobacco use may not be limited only to cigarette smoking. There is evidence to suggest that heavy use of alternative smoking products, including smokeless tobacco (oral moist snuff, "snus"), may also impact diabetes development $[46,47]$. A prospective population based study of Swedish men demonstrated an increased risk for the development of T2D in individuals who used $>5$ boxes of snus per week (odds ratio: 3.3, CI 1.4-8.1) [47]. In a second study, also performed in Sweden, high consumption of smokeless tobacco ("snus") predicted an increased risk of type 2 diabetes in a 10-year prospective study of middle-aged men. In contrast, another Swedish study failed to find an association between snus use and T2D [48]. However, more recently a pooled analysis from five cohorts revealed a hazard ratio of incident type 2 diabetes of 1.15 (95\% CI: 1.00-1.32) in current users of snus compared to never users. Moreover, risk increased with heavier weekly use [49]. In aggregate, these findings appear to support an increased risk of diabetes with smokeless tobacoo at least in the the Swedish population, but further studies are needed to determine how applicable these findings are to other populations and ethnic groups.

\section{Developmental effects of smoking}

Smoking during pregnancy is associated with an increased risk of gestational diabetes mellitus (adjusted odds ratio $=1.9,95 \%$ CI: 1.0, 3.6) [50]. Moreover, the incidence of diabetes in offspring may be affected by exposure to smoke in utero. For example, the 1958 British Birth Cohort study measured Hb1 Ac levels in participants at age 45, and observed that maternal smoking was associated with an increase in the prevalence of $\mathrm{HbA1C}>6 \%$ and development of T2D in adulthood [51]. Likewise, data from 34,453 participants in the Nurses' Health Study II revealed that maternal (and to a lesser extent, paternal) smoking during the first trimester was an independent risk factor for the development of T2D in offspring, even after adjusting for confounders such as birth weight and later-life BMI (hazard ratio 1.34, 9\% CI 1.01-1.76) [52]. Analysis from the Prospective Singleton Pregnancy Cohort showed slightly higher proinsulin-to-insulin ratios in offspring of smokers compared to nonsmokers, suggesting alterations in pancreatic $\beta$ cell function and potentially increased $\beta$ cell stress at birth (35). Finally, offspring of rats exposed to nicotine exhibited altered insulin biosynthesis, $\beta$ cell degranulation, increased islet oxidative stress, and impaired glucose-stimulated insulin secretion, all of which were preceded by the appearance of mitochondrial structural abnormalities [53]. Furthermore, exposure to secondhand (passive) cigarette smoke after the prenatal period is also linked to an increased risk for T2D development. A recent meta-analysis of prospective studies including almost 6 million individuals reported a $22 \%$ increase in the risk for development of T2D in those never 
smokers exposed to passive smoke compared to never smokers not exposed to passive smoke [54]

\section{Smoking Cessation and Glucose Homeostasis}

Active smoking has been associated with reduced appetite and weight loss. On the other hand, smoking cessation is often associated with weight gain. In some studies, cessation of cigarette smoking has also been linked to increased incidence of T2D, likely due to increased weight gain upon withdrawl of nicotine, and this increased risk of T2D was highest in the first 3 years post-cessation [55]. Previous studies have suggested significant heterogeneity in the magnitude of weight gain following smoking cessation, with the greatest weight gain often seen in individuals with the highest daily cigarette consumption [56]. Studies of gender-related differences in post-cessation weight gain (PCWG) have yielded conflicting results, with some studies showing greater weight gain in men and others showing higher weight gain in women $[57,58]$. Self-report data from the NHANES study revealed an average PCWG of approximately $1.4 \mathrm{~kg}$ (95\% CI: 0.8 to 2.0$)$ in recent quitters who had stopped smoking within the past year. In this study, normal and overweight individuals were at greatest risk of weight gain, while obese individuals tended to lose a small but insignificant amount of weight [59]. Mean one-year weight gain in another sedentary group of smokers was documented to be between 3.3-3.9 $\mathrm{kg}$ [57]. While the effects of smoking cessation on glucose homeostasis may be often confounded by the presence of weight gain, at least one study has shown that prior to any change in weight, short-term smoking cessation of 1-2 weeks was sufficient to reverse defects in insulin sensitivity and skeletal muscle insulin signaling in both male and female young adults [33]. Longer term studies are needed to define how these parameters change over time.

Varenicline is a partial nicotine receptor agonist that has been shown to promote smoking cessation, with abstinence rates up to two- or three-fold higher compared with nonpharmacological means. Similarly, buproprion, an anti-depressant, and nicotine replacement therapy via a patch or gum have been shown to be more efficacious in promoting abstinence compared to placebo treatment [60]. A Cochrane systematic review suggested that personalized weight support and counseling may successfully reduce post-cessation weight gain. Buproprion, varenicline, and nicotine replacement therapy have also been shown attenuate weight gain acutely during active treatment; yet it is unclear whether such therapies can help control weight in the long term [61]. Moreover, given studies suggesting an independent effect of nicotine to perturb glucose homeostasis, it remains to be clarified whether cessation strategies that include nicotine agonists differentially impact long-term changes in glucose homeostasis. Interestingly, in vitro treatment of INS-1 $\beta$ cells with nicotine, varenicline, and bupropion led to decreased levels of glucose-stimulated insulin secretion with each agent, suggesting that further studies to address these questions are needed [62].

The clear association between T2D risk and disease severity underscore the importance of promoting smoking cessation in indvidiuals with T2D. However, many persons with T2D continue to smoke, despite these contraindications. Increasing rodent and human evidence indicates that T2D may increase the rewarding effects of dopamine, as disrupted insulin 
signaling during T2D suppresses dopamine signaling in the mesolimbic reward pathway [63].

\section{Conclusions}

Epidemiological studies demonstrate a clear association between cigarette smoking and an increased risk of T2D, whereas clinical data suggest an effect of smoking and nicotine on body composition, insulin sensitivity, and pancreatic $\beta$ cell function. Human, rodent, and in vitro studies have begun to yield insight into the molecular mechanisms through which nicotine and smoking exposure impact glucose homeostasis. However, a complete understanding of the underlying pathways impacted by tobacco abuse, especially mechanistic studies focused on the pancreatic $\beta$ cell, are lacking. Not withstanding these unknowns, this comprehensive review of available literature suggests that smoking should be elevated to the category of a recognized and modifiable risk factor for the development of diabetes, uniformly across all diabetes organizations and that smoking status should be considered as an indication for diabetes screening. Moreover, smoking cessation along with weight control post cessation should be promoted as an essential public health practice for diabetes prevention.

\section{Acknowledgments}

This work was supported by NIH grant DK093954 (to C.E-M.) and F32 DK104501 (to E. A-B) and VA Merit Award I01 BX001733 (to C.E-M.). The contents of this article are solely the responsibility of the authors and do not necessarily represent the official views of the National Institutes of Health, the U.S. Department of Veterans Affairs or the United States Government. The authors have no competing interests to disclose.

\section{References}

1. World Health Organization. [Accessed February 2017] http://www.who.int/topics/ diabetes_mellitus/en/

2. The Health Consequences of Smoking-50 Years of Progress: A Report of the Surgeon General. Atlanta (GA): 2014.

3. World Health Organization. [Accessed February 2017] Global Report on Diabetes. http:// www.who.int/diabetes/global-report/en/

4. Auerbach S, Filer D, Reif D, Walker V, Holloway AC, Schlezinger J, et al. Prioritizing Environmental Chemicals for Obesity and Diabetes Outcomes Research: A Screening Approach Using ToxCast High-Throughput Data. Environmental health perspectives. 2016; 124:1141-54. [PubMed: 26978842]

5. [Accessed February 2017] International Diabetes. www.idf.org

6. Saeed AA. Association of tobacco products use and diabetes mellitus-results of a national survey among adults in saudi arabia. Balkan medical journal. 2012; 29:247-51. [PubMed: 25207009]

7. Willi C, Bodenmann P, Ghali WA, Faris PD, Cornuz J. Active smoking and the risk of type 2 diabetes: a systematic review and meta-analysis. Jama. 2007; 298:2654-64. [PubMed: 18073361]

8. Rimm EB, Chan J, Stampfer MJ, Colditz GA, Willett WC. Prospective study of cigarette smoking, alcohol use, and the risk of diabetes in men. BMJ. 1995; 310:555-9. [PubMed: 7888928]

9. Shi L, Shu XO, Li H, Cai H, Liu Q, Zheng W, et al. Physical activity, smoking, and alcohol consumption in association with incidence of type 2 diabetes among middle-aged and elderly Chinese men. PLoS One. 2013; 8:e77919. [PubMed: 24223743]

10. Luo J, Rossouw J, Tong E, Giovino GA, Lee CC, Chen C, et al. Smoking and diabetes: does the increased risk ever go away? American journal of epidemiology. 2013; 178:937-45. [PubMed: 23817918] 
11. Jee SH, Foong AW, Hur NW, Samet JM. Smoking and risk for diabetes incidence and mortality in Korean men and women. Diabetes care. 2010; 33:2567-72. [PubMed: 20823342]

12. Sargeant LA, Khaw KT, Bingham S, Day NE, Luben RN, Oakes S, et al. Cigarette smoking and glycaemia: the EPIC-Norfolk Study. European Prospective Investigation into Cancer. International journal of epidemiology. 2001; 30:547-54. [PubMed: 11416081]

13. Clair C, Bitton A, Meigs JB, Rigotti NA. Relationships of cotinine and self-reported cigarette smoking with hemoglobin A1c in the U.S.: results from the National Health and Nutrition Examination Survey, 1999-2008. Diabetes Care. 2011; 34:2250-5. [PubMed: 21836101]

14. Somm E. Nicotinic cholinergic signaling in adipose tissue and pancreatic islets biology: revisited function and therapeutic perspectives. Arch Immunol Ther Exp (Warsz). 2014; 62:87-101. [PubMed: 24276790]

15. Phillips WD. Acetylcholine receptors and the cytoskeletal connection. Clinical and experimental pharmacology \& physiology. 1995; 22:961-5. [PubMed: 8846518]

16. Zoli M, Picciotto MR. Nicotinic regulation of energy homeostasis. Nicotine Tob Res. 2012; 14:1270-90. [PubMed: 22990212]

17. Kimura K, Tanida M, Nagata N, Inaba Y, Watanabe H, Nagashimada M, et al. Central Insulin Action Activates Kupffer Cells by Suppressing Hepatic Vagal Activation via the Nicotinic Alpha 7 Acetylcholine Receptor. Cell Rep. 2016; 14:2362-74. [PubMed: 26947072]

18. Epifano L, Di Vincenzo A, Fanelli C, Porcellati F, Perriello G, De Feo P, et al. Effect of cigarette smoking and of a transdermal nicotine delivery system on glucoregulation in type 2 diabetes mellitus. Eur J Clin Pharmacol. 1992; 43:257-63. [PubMed: 1425888]

19. Chiba M, Masironi R. Toxic and trace elements in tobacco and tobacco smoke. Bull World Health Organ. 1992; 70:269-75. [PubMed: 1600587]

20. Rhee SY, Hwang YC, Woo JT, Chin SO, Chon S, Kim YS. Arsenic exposure and prevalence of diabetes mellitus in Korean adults. Journal of Korean medical science. 2013; 28:861-8. [PubMed: 23772150]

21. Pan WC, Seow WJ, Kile ML, Hoffman EB, Quamruzzaman Q, Rahman M, et al. Association of low to moderate levels of arsenic exposure with risk of type 2 diabetes in Bangladesh. American journal of epidemiology. 2013; 178:1563-70. [PubMed: 24049161]

22. Feseke SK, St-Laurent J, Anassour-Sidi E, Ayotte P, Bouchard M, Levallois P. Arsenic exposure and type 2 diabetes: results from the 2007-2009 Canadian Health Measures Survey. Health promotion and chronic disease prevention in Canada. 2015; 35:63-72. [PubMed: 26083521]

23. Moon SS. Association of lead, mercury and cadmium with diabetes in the Korean population: the Korea National Health and Nutrition Examination Survey (KNHANES) 2009-2010. Diabetic medicine: a journal of the British Diabetic Association. 2013; 30:e143-8. [PubMed: 23278294]

24. Thayer KA, Heindel JJ, Bucher JR, Gallo MA. Role of environmental chemicals in diabetes and obesity: a National Toxicology Program workshop review. Environmental health perspectives. 2012; 120:779-89. [PubMed: 22296744]

25. Fujiyoshi A, Miura K, Kadowaki S, Azuma K, Tanaka S, Hisamatsu T, et al. Lifetime cigarette smoking is associated with abdominal obesity in a community-based sample of Japanese men: The Shiga Epidemiological Study of Subclinical Atherosclerosis (SESSA). Prev Med Rep. 2016; 4:225-32. [PubMed: 27413686]

26. Yun JE, Kimm H, Choi YJ, Jee SH, Huh KB. Smoking is associated with abdominal obesity, not overall obesity, in men with type 2 diabetes. J Prev Med Public Health. 2012; 45:316-22. [PubMed: 23091657]

27. Canoy D, Wareham N, Luben R, Welch A, Bingham S, Day N, et al. Cigarette smoking and fat distribution in 21,828 British men and women: a population-based study. Obes Res. 2005; 13:1466-75. [PubMed: 16129730]

28. Frati AC, Iniestra F, Ariza CR. Acute effect of cigarette smoking on glucose tolerance and other cardiovascular risk factors. Diabetes Care. 1996; 19:112-8. [PubMed: 8718429]

29. Targher G, Alberiche M, Zenere MB, Bonadonna RC, Muggeo M, Bonora E. Cigarette smoking and insulin resistance in patients with noninsulin-dependent diabetes mellitus. The Journal of clinical endocrinology and metabolism. 1997; 82:3619-24. [PubMed: 9360516] 
30. Morimoto A, Tatsumi Y, Deura K, Mizuno S, Ohno Y, Watanabe S. Impact of cigarette smoking on impaired insulin secretion and insulin resistance in Japanese men: The Saku Study. Journal of diabetes investigation. 2013; 4:274-80. [PubMed: 24843666]

31. Ostgren CJ, Lindblad U, Ranstam J, Melander A, Rastam L, Skaraborg H, et al. Associations between smoking and beta-cell function in a non-hypertensive and non-diabetic population. Skaraborg Hypertension and Diabetes Project. Diabetic medicine: a journal of the British Diabetic Association. 2000; 17:445-50. [PubMed: 10975213]

32. Bergman BC, Perreault L, Hunerdosse DM, Koehler MC, Samek AM, Eckel RH. Intramuscular lipid metabolism in the insulin resistance of smoking. Diabetes. 2009; 58:2220-7. [PubMed: 19581421]

33. Bergman BC, Perreault L, Hunerdosse D, Kerege A, Playdon M, Samek AM, et al. Novel and reversible mechanisms of smoking-induced insulin resistance in humans. Diabetes. 2012; 61:3156-66. [PubMed: 22966072]

34. Sztalryd C, Hamilton J, Horwitz BA, Johnson P, Kraemer FB. Alterations of lipolysis and lipoprotein lipase in chronically nicotine-treated rats. Am J Physiol. 1996; 270:E215-23. [PubMed: 8779941]

35. Wu Y, Song P, Zhang W, Liu J, Dai X, Liu Z, et al. Activation of AMPKalpha2 in adipocytes is essential for nicotine-induced insulin resistance in vivo. Nature medicine. 2015; 21:373-82.

36. Eliasson B, Attvall S, Taskinen MR, Smith U. The insulin resistance syndrome in smokers is related to smoking habits. Arteriosclerosis and thrombosis: a journal of vascular biology/American Heart Association. 1994; 14:1946-50.

37. Hamabe A, Uto H, Imamura Y, Kusano K, Mawatari S, Kumagai K, et al. Impact of cigarette smoking on onset of nonalcoholic fatty liver disease over a 10-year period. J Gastroenterol. 2011; 46:769-78. [PubMed: 21302121]

38. Besingi W, Johansson A. Smoke-related DNA methylation changes in the etiology of human disease. Human molecular genetics. 2014; 23:2290-7. [PubMed: 24334605]

39. Ligthart S, Steenaard RV, Peters MJ, van Meurs JB, Sijbrands EJ, Uitterlinden AG, et al. Tobacco smoking is associated with DNA methylation of diabetes susceptibility genes. Diabetologia. 2016; 59:998-1006. [PubMed: 26825526]

40. Stagner JI, Samols E. Modulation of insulin secretion by pancreatic ganglionic nicotinic receptors. Diabetes. 1986; 35:849-54. [PubMed: 2874091]

41. Ejiri K, Taniguchi H, Ishihara K, Hara Y, Baba S. Possible involvement of cholinergic nicotinic receptor in insulin release from isolated rat islets. Diabetes Res Clin Pract. 1990; 8:193-9. [PubMed: 1971210]

42. Yoshikawa H, Hellstrom-Lindahl E, Grill V. Evidence for functional nicotinic receptors on pancreatic beta cells. Metabolism: clinical and experimental. 2005; 54:247-54. [PubMed: 15690320]

43. Yildiz D. Nicotine, its metabolism and an overview of its biological effects. Toxicon. 2004; 43:619-32. [PubMed: 15109883]

44. Wilkins JN, Carlson HE, Van Vunakis H, Hill MA, Gritz E, Jarvik ME. Nicotine from cigarette smoking increases circulating levels of cortisol, growth hormone, and prolactin in male chronic smokers. Psychopharmacology. 1982; 78:305-8. [PubMed: 6818588]

45. Tweed JO, Hsia SH, Lutfy K, Friedman TC. The endocrine effects of nicotine and cigarette smoke. Trends Endocrinol Metab. 2012; 23:334-42. [PubMed: 22561025]

46. Persson PG, Carlsson S, Svanstrom L, Ostenson CG, Efendic S, Grill V. Cigarette smoking, oral moist snuff use and glucose intolerance. Journal of internal medicine. 2000; 248:103-10. [PubMed: 10947888]

47. Ostenson CG, Hilding A, Grill V, Efendic S. High consumption of smokeless tobacco ("snus") predicts increased risk of type 2 diabetes in a 10-year prospective study of middle-aged Swedish men. Scand J Public Health. 2012; 40:730-7. [PubMed: 23117209]

48. Eliasson M, Asplund K, Nasic S, Rodu B. Influence of smoking and snus on the prevalence and incidence of type 2 diabetes amongst men: the northern Sweden MONICA study. Journal of internal medicine. 2004; 256:101-10. [PubMed: 15257722] 
49. Carlsson S, Andersson T, Araghi M, Galanti R, Lager A, Lundberg M, et al. Smokeless tobacco (snus) is associated with an increased risk of type 2 diabetes: results from five pooled cohorts. Journal of internal medicine. 2017

50. England LJ, Levine RJ, Qian C, Soule LM, Schisterman EF, Yu KF, et al. Glucose tolerance and risk of gestational diabetes mellitus in nulliparous women who smoke during pregnancy. Am J Epidemiol. 2004; 160:1205-13. [PubMed: 15583373]

51. Thomas C, Hypponen E, Power C. Prenatal exposures and glucose metabolism in adulthood: are effects mediated through birth weight and adiposity? Diabetes care. 2007; 30:918-24. [PubMed: 17277041]

52. Jaddoe VW, de Jonge LL, van Dam RM, Willett WC, Harris H, Stampfer MJ, et al. Fetal exposure to parental smoking and the risk of type 2 diabetes in adult women. Diabetes care. 2014; 37:296673. [PubMed: 25092685]

53. Bruin JE, Petre MA, Raha S, Morrison KM, Gerstein HC, Holloway AC. Fetal and neonatal nicotine exposure in Wistar rats causes progressive pancreatic mitochondrial damage and beta cell dysfunction. PLoS One. 2008; 3:e3371. [PubMed: 18852877]

54. Pan A, Wang Y, Talaei M, Hu FB, Wu T. Relation of active, passive, and quitting smoking with incident type 2 diabetes: a systematic review and meta-analysis. Lancet Diabetes Endocrinol. 2015; 3:958-67. [PubMed: 26388413]

55. Yeh HC, Duncan BB, Schmidt MI, Wang NY, Brancati FL. Smoking, smoking cessation, and risk for type 2 diabetes mellitus: a cohort study. Annals of internal medicine. 2010; 152:10-7. [PubMed: 20048267]

56. Komiyama M, Wada H, Ura S, Yamakage H, Satoh-Asahara N, Shimatsu A, et al. Analysis of factors that determine weight gain during smoking cessation therapy. PLoS One. 2013; 8:e72010. [PubMed: 23991026]

57. Prod'hom S, Locatelli I, Giraudon K, Marques-Vidal P, Clair C, Bize R, et al. Predictors of weight change in sedentary smokers receiving a standard smoking cessation intervention. Nicotine Tob Res. 2013; 15:910-6. [PubMed: 23048177]

58. O’Hara P, Connett JE, Lee WW, Nides M, Murray R, Wise R. Early and late weight gain following smoking cessation in the Lung Health Study. Am J Epidemiol. 1998; 148:821-30. [PubMed: 9801011]

59. Krukowski RA, Bursac Z, Little MA, Klesges RC. The Relationship between Body Mass Index and Post-Cessation Weight Gain in the Year after Quitting Smoking: A Cross-Sectional Study. PLoS One. 2016; 11:e0151290. [PubMed: 26977598]

60. Cahill K, Lindson-Hawley N, Thomas KH, Fanshawe TR, Lancaster T. Nicotine receptor partial agonists for smoking cessation. Cochrane Database Syst Rev. 2016:CD006103. [PubMed: 27158893]

61. Farley AC, Hajek P, Lycett D, Aveyard P. Interventions for preventing weight gain after smoking cessation. Cochrane Database Syst Rev. 2012; 1:CD006219. [PubMed: 22258966]

62. Woynillowicz AK, Raha S, Nicholson CJ, Holloway AC. The effect of smoking cessation pharmacotherapies on pancreatic beta cell function. Toxicology and applied pharmacology. 2012; 265:122-7. [PubMed: 22960054]

63. O'Dell LE, Nazarian A. Enhanced vulnerability to tobacco use in persons with diabetes: A behavioral and neurobiological framework. Prog Neuropsychopharmacol Biol Psychiatry. 2016; 65:288-96. [PubMed: 26092247] 